\title{
TURISMO PEDAGÓGICO: FAVORECIMENTO DA APRENDIZAGEM NO ENSINO SUPERIOR A PARTIR DO OLHAR DISCENTE
}

\author{
Jaqueline Calheiros Calado ${ }^{1}$ \\ Jesislaine Germano de França ${ }^{2}$ \\ Luiz Buarque de Gusmão Filho ${ }^{3}$ \\ Adryanne Maria R. B. de Assis ${ }^{4}$
}

\section{RESUMO}

O presente trabalho foi elaborado para compreender as práticas de turismo utilizadas em uma instituição de ensino superior no município de Jaboatão de Guararapes como método de ensino e aprendizagem para os alunos, tendo como estudo de caso a agência Paradise Turismo como vetor desse processo, localizada no mesmo município. Foram analisadas as possíveis contribuições das visitas técnicas na formação dos estudantes. A metodologia deste estudo consistiu em uma pesquisa de campo em que foi aplicado um questionário com alunos de diversos cursos. Dessa maneira, a pesquisa permitiu analisar as contribuições das visitas técnicas na formação desses estudantes a partir da experiência do Projeto de Extensão Universitária da Paradise Turismo.

Palavras-chave: Turismo Pedagógico. Ensino e Aprendizagem. Formação acadêmica. Ensino superior.

Data de submissão: $16 / 02 / 2020$

Data de aprovação: 04/03/2020

\section{INTRODUÇÃO}

O turismo pedagógico tem como finalidade utilizar os conceitos trabalhados em sala de aula de maneira lúdica e específica, como uma ferramenta que auxilia no sistema de ensino, juntando a teoria com a prática no contexto educacional, podendo ser considerado como um facilitador no processo de ensino e aprendizagem. O turismo pedagógico, também chamado de turismo educacional, pode se desenvolver em várias áreas do conhecimento, atuando como um instrumento transversal no desenvolvimento da aprendizagem, ou seja, podendo haver diferentes disciplinas engajadas dentro do contexto de um mesmo trabalho.

\footnotetext{
1 Graduanda do curso de Licenciatura em Pedagogia na Faculdade Metropolitana da Grande Recife. E-mail: jaquelinecalheiros2014@gmail.com

2 Graduanda do curso de Licenciatura em Pedagogia na Faculdade Metropolitana da Grande Recife.

3 Coorientador/Professor da FMGR. E-mail: professorbuarque@gmail.com

4 Orientadora/Professora da FMGR. E-mail: adryanne@gmail.com
} 
Dessa forma, acreditamos que a prática educacional aplicada é uma excelente forma de fazer com que o estudante busque conhecimento referente ao que lhe interessa e lhe desperte a curiosidade. Nessa busca de informações, o aluno passa a ter um olhar mais crítico e reflexivo dentro do meio no qual está se inserindo.

De acordo com Cunha (2010),

A prática, cada vez mais, vem sendo valorizada como espaço de construção de saberes, quer na formação dos professores, quer na aprendizagem dos alunos. Entretanto, a prática, que é fonte de sabedoria, é que torna a experiência um ponto de reflexão. (CUNHA, 2010, p. 52).

Sendo assim, o turismo educacional passa a ser um vetor de mudanças, colaborando para tornar as aulas mais dinâmicas e atrativas, em que pode se desenvolver uma valorização escolar, social e cultural do aluno. Dessa forma, tais atividades turísticas podem proporcionar uma reflexão sobre o papel do estudante dentro de cada setor.

Entende-se que o processo de ensino e aprendizagem trabalhado sobre a ótica do turismo nos dias atuais é pensar em uma educação voltada para as aprendizagens significativas em um mundo globalizado.

Partindo desse contexto, este trabalho tem como objetivo realizar uma análise pedagógica do projeto de extensão universitária da Paradise Turismo a fim de observar as contribuições das visitas técnicas na formação dos estudantes.

Para levantamento dos dados foi elaborado um questionário (apêndice A) que permite verificar, a partir do olhar dos estudantes, se as atividades de extensão propostas proporcionavam um melhor aprendizado dos conteúdos trabalhados em sala de aula.

O questionário foi encaminhado para 60 estudantes. Desse total, 45 responderam que já participaram de visitas técnicas.

\section{HISTÓRICO DO TURISMO NO MUNDO}

O turismo teve sua origem na Grécia, entre os povos Fenícios e Romanos, pois acredita-se que esses foram os primeiros viajantes, tendo como objetivo o comércio.

Até hoje o turismo possui inúmeras definições, segundo diversos autores, que abordam diferentes tipos de conceituações aplicadas aos seus estudos. Barreto (2003) explica que:

Em outros fenômenos sociais que podem ser de alguma forma comparáveis ao turismo, existem diferentes definições para os elementos intervenientes. Há, por exemplo, (...) definições claras para sistema habitacional, construção, engenharia civil, negócios imobiliários, ou para sistema hospitalar, doenças, medicina. Não acontece o mesmo atualmente com o turismo. Chama-se turismo tanto ao ato praticado pelos turistas, quanto ao sistema comercial montado para transladá-los, hospedá-los, entretê-los, aos serviços prestados dentro desse sistema, e à série de 
relações comerciais, políticas e sociais que acontecem a partir desse ato praticado pelos turistas. (BARRETO, 2003, p. 19).

A Organização Mundial de Turismo (OMT) define turismo como um fenômeno de atividades em que pessoas realizam durante suas viagens e que têm permanência em lugares diferentes do local de origem, por um período menor que um ano consecutivo e que tenha como fins lazer, negócios, entre outros.

Moesch (2005) discorda da OMT, tendo como base o fato de somente a permanência de um indivíduo em um local diferente de seu ambiente natural ser classificada como turismo. Ela trata o turismo como uma ferramenta utilizada pelo indivíduo de determinada localidade para a vivência de práticas sociais e culturais que podem estar aplicadas ao seu próprio entorno, desconsiderando, assim, o deslocamento para fora de seu ambiente natural, fazendo com que se pense em um turismo não somente para o visitante externo, como também para o residente local, conceituando o termo turista cidadão. Para a autora,

\begin{abstract}
O turista cidadão é aquele morador da localidade que vivencia práticas sociais, no seu tempo rotineiro, dentro de sua cidade, de forma não rotineira, onde é provado em relação à cidade. Turista cidadão é aquele que resgata a cultura da sua cidade fazendo uso do estranhamento da mesma. Este estranhamento inicia no momento em que o indivíduo descobre no espaço cotidiano outras culturas, outras formas étnicas e outras oportunidades de lazer e entretenimento. Quando se encontra na situação de turista cidadão este sujeito aprende a utilizar os espaços ambientais, culturais, históricos, comerciais e de entretenimento com uma percepção diferenciada do seu cotidiano. (MOESCH et al., 2005 apud GASTAL, 2006, p. 12).
\end{abstract}

O turismo é uma atividade extremamente estudada e, por se tratar de uma atividade que movimenta outros setores ligados a ela, torna-se uma atividade ainda mais complexa. Segundo Beni (2001, p. 36), o turismo está ligado à soma dos fenômenos e das relações resultantes da viagem e da permanência de não residentes, na medida em que não leva à residência permanente e não está relacionada a nenhuma atividade remuneratória. Ou seja, turismo, necessariamente, é quando o indivíduo passa mais de 24 horas em um local fora de sua residência fixa, desde que este indivíduo não seja remunerado pelas atividades geradas dentro desse deslocamento.

Para Damasceno (2006), o turismo é considerado uma atividade econômica que abrange várias áreas como o turismo pedagógico, que é feito com a finalidade do conhecimento que pode ser abrangido na mesma localidade, ou seja, na mesma cidade em que o indivíduo mora, pois, o mesmo tem como objetivo explorar o lugar com uma determinada finalidade.

Neste sentido pode-se concluir que o turismo tem como objetivo realizar a viagem de um local para outro, podendo utilizar o próprio entorno do cidadão, sem que o mesmo tenha 
necessariamente que se ausentar de sua região, durando o tempo necessário para a conclusão das atividades. É necessário que dentro desta ação estejam envolvidos os equipamentos turísticos do local para o desenvolvimento social, cultural, aprendizado e valorização da região envolvida no processo.

Justamente pelo fato do turismo se encontrar ligado a diversas áreas é possível verificar que não se pode defini-lo em somente um segmento, uma vez que possui várias subáreas e o mercado turístico se divide em diversos tipos.

O Ministério do Turismo (MTUR, 2010) prevê que no Brasil o mercado turístico atua em pelo menos doze segmentos. Neles estão aplicados os padrões geográficos, sociais, culturais, naturais e econômicos dos destinos turísticos.

Desde os primórdios o turismo se tornou objeto de estudo, pois o mesmo está ligado dentro de uma cadeia produtiva econômica em que se pode mudar a economia de qualquer localidade. Como afirma Barreto (2001),

\begin{abstract}
A economia foi a primeira disciplina a estudar o turismo, porque, nas primeiras décadas deste século, percebeu-se, na Europa, que o turismo era fonte de divisas. A importância teórica do turismo (que supera amplamente a quantidade de estudos sobre o turismo feitos por outras ciências) fez com que, inclusive no Brasil, na década de 1980, no auge das discussões sobre a regulamentação da profissão de "turismólogo", os economistas se opusessem, dizendo que o turismo devia ser um ramo desta última ciência. (BARRETO et al., 2001 apud CUNHA, 2002, p. 01).
\end{abstract}

É válido ressaltar que o mais importante no turismo é o conhecimento adquirido pelo indivíduo. Esta é a principal fonte de se obter informações entre as nações, como destacam Lickoris e Jenkin (2000). Isso pode ser relacionado a estudos que mostram que no século XVI o homem passa a sentir a necessidade de descobrir o mundo, tendo como meio para isso as grandes viagens internacionais e multiculturais que os levassem a ter conhecimento sobre as diversas artes, ciências e literaturas.

\title{
Histórico do turismo pedagógico no mundo
}

Os europeus buscavam conhecer outros lugares, surgindo a popularização do termo grand tour que referencia uma grande viagem, fazendo assim com que houvesse um grande movimento de pessoas por todas as partes da Europa que tinham o objetivo de viajar, tanto por motivos de lazer ou estudos. Tal ação tornou-se uma prática comum entre os jovens da alta classe europeia que se utilizavam das viagens para obter conhecimento em outras cidades e países juntamente com seus tutores, tornando as viagens um meio de alcançar a educação desses jovens, bem como proporcioná-los, além de lazer, um intercâmbio entre as diversas culturas. (REJOWSKI, 2002). 
Essa prática somente passou a ser desenvolvida nos séculos XVII e XVIII, em que a educação entre as famílias inglesas era somente considerada completa mediante o período de um a três anos de viagem pela Europa entre os jovens ingleses e seus tutores.

Ao longo dos anos as viagens de estudos passaram a ser denominadas de "turismo educacional ou pedagógico", pois têm como característica fazer com que os estudantes aprendam e desenvolvam na prática o que foi passado como teoria. Ao turismo cabe um importante papel no processo de aprendizagem: agir como facilitador na prática do ensino.

O turismo pedagógico era utilizado apenas como uma forma que os jovens buscavam para adquirir novos conhecimentos em estudos e vivenciavam novas culturas, além do lazer que era disposto durante as viagens.

Sendo assim, podemos verificar a existência da pedagogia inserida no turismo desde os primórdios, utilizando a prática turística como caminho para se alcançar o conhecimento, aproveitando a oportunidade para trabalhar de forma interativa e transversal a teoria juntamente com a prática.

A atividade turístico-pedagógica vem em constante crescimento, sendo aplicada dentro do conteúdo curricular através de visitas técnicas multidisciplinares, visando à possibilidade da troca de conhecimento entre professores e alunos, bem como entre alunos e profissionais das áreas em que os trabalhos podem ser desenvolvidos.

\section{TIPOS DE TURISMO}

Dentro da cadeia do turismo há vários tipos de atividades com formas e qualidades diferentes, classificando-se de acordo com as suas estruturas e finalidades. A importância da classificação dos tipos de turismo demonstra grande valor para a organização de sua cadeia produtiva. Segundo Oliveira (2005), pode-se classificar e definir os tipos de turismo como:

- Turismo de lazer. É um turismo ligado às pessoas que gostam de viajar sem muitas finalidades, apenas com o objetivo de se divertir e conhecer outros lugares. Pode ser aplicado em diversas ocasiões, como viajar de carro com a família ou em excursões organizadas por agências de viagens, por exemplo.

- Turismo de águas termais. É praticado por pessoas que buscam cuidar da saúde através de estâncias hidrominerais ou mesmo por recreação. Essa atividade é considerada como turismo sofisticado e localizado. 
- Turismo social. É um tipo de turismo mais ligado às pessoas de baixa renda e que não têm muito acesso a opções de lazer, ficando limitado a lugares que gerem pouco custo.

- Turismo rural. É praticado fora dos centros urbanos, proporcionando aos visitantes a estrutura própria da zona rural, unindo atividades do campo a belas paisagens naturais.

\section{Turismo Pedagógico}

O turismo pedagógico é conceituado em função das concepções trabalhadas de maneira lúdica e diferente, sendo uma atividade para auxiliar no sistema de ensino, juntando a teoria e a prática no âmbito educacional. Com isso, o mesmo, por incluir o indivíduo com o ambiente físico, geográfico ou ecológico, é um meio facilitador para o desenvolvimento de ensino e aprendizagem que acaba se tornando um estímulo para o aprendiz.

Essa atividade, por fazer parte de várias áreas do conhecimento, vem sendo atualmente considerada como um instrumento inovador no desenvolvimento diferencial dos educandos, ganhando espaço no ambiente escolar com incentivo de um novo método de construção de conhecimento. Cabe, assim, aos educadores, buscarem novas alternativas para que a aprendizagem ocorra junto com a ligação da teoria e da prática.

O turismo voltado para a atividade pedagógica possibilita a aplicabilidade e a verificação dos conceitos trabalhados em sala, uma vez que são os componentes do ambiente da aprendizagem que dão origem à estimulação para o aluno. (GAGNÉ et al., 1971, p. 247, apud JUNQUEIRA \& SCREMIN, 2012).

Os alunos sentem a necessidade de inovação no aprendizado para que este se torne um vetor de transformação na aprendizagem. Sendo assim, o turismo pode ser utilizado como ferramenta, fazendo com que se torne um incentivo nos estudos.

Beni (2001), a respeito do turismo pedagógico, diz que uma viagem cultural se dá mediante o acompanhamento de professores especializados da própria instituição de ensino com programas de aulas e visitas a pontos históricos ou de interesse para o desenvolvimento educacional dos estudantes. $\mathrm{O}$ autor mostra que quem trabalha com a ferramenta do turismo pedagógico são os próprios professores que têm experiência própria na aérea e que acreditam que as visitas técnicas, como são conhecidas, colaboram com o desenvolvimento da aprendizagem dos estudantes. 


\section{APRESENTAÇÃO E ANÁLISE DOS RESULTADOS}

Os alunos pesquisados são dos cursos de Direito, Gastronomia, Recursos Humanos e Pedagogia. Dos 60 estudantes participantes, 45 responderam que já fizeram viagens e/ou visitas técnicas pela faculdade com a Paradise Turismo. Assim, esta pesquisa tem como foco os estudantes que já participaram de alguma atividade extensionista através da referida agência.

Em relação à questão número 2 do questionário (Os seus professores já realizaram atividades no ambiente externo da faculdade?) apenas três alunos $(6,7 \%)$ responderam de forma negativa, porém já participaram de atividades no ambiente externo da faculdade com professores diferentes de seus cursos. Sendo assim, permaneceram como objeto de estudo. Solicitados a citar as atividades realizadas, as mais destacadas foram: São Benedito do Sul (24,4\%), Coca-Cola (20,0\%), Cachaçaria Sanhaçu (17,8\%), Museus (17,8\%), Baía da Traição $(15,6 \%)$ e Brejo da Madre de Deus (15,6\%). As demais atividades citadas tiveram percentuais que variaram de $2,2 \%$ a $6,7 \%$, conforme visto no gráfico 1 .

Gráfico 1 - Frequências percentuais das atividades realizadas no ambiente externo da faculdade

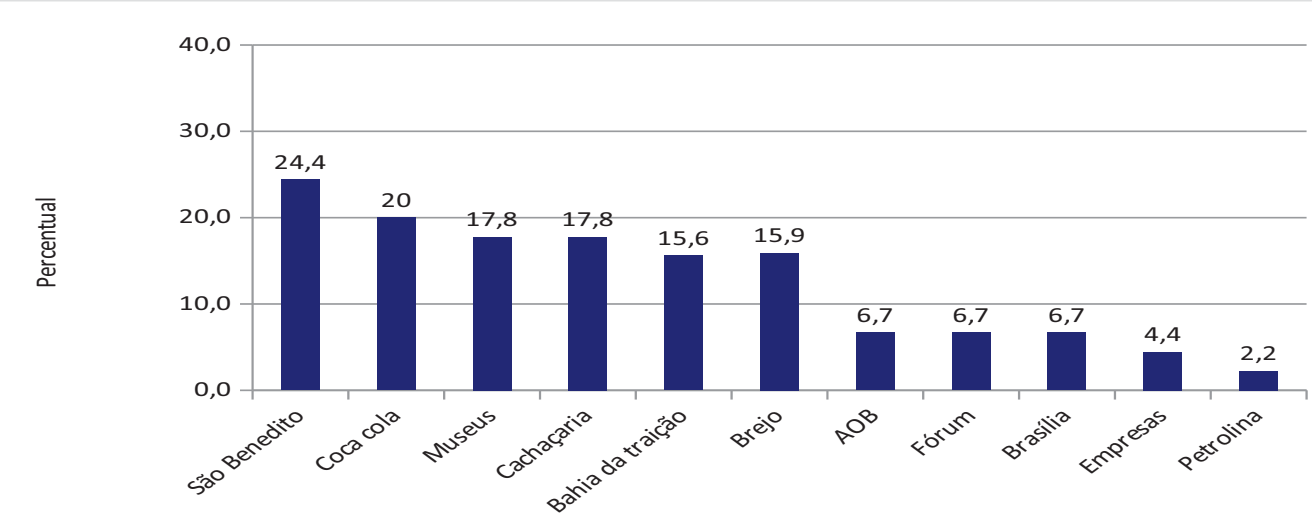

Atividades realizadas no ambiente externo da faculdade

Fonte: os autores

Dos resultados obtidos na Tabela 1, percebe-se que na primeira questão (Em sua opinião as viagens e/ou visitas técnicas colaboraram com a aprendizagem do conteúdo trabalhado em sala de aula?) a resposta mais frequente foi "colaboraram muito" $(77,8 \%)$, "razoavelmente" $(8,9)$ e "colaboraram pouco" $(8,9)$. Apenas um estudante $(2,2 \%)$ respondeu que as viagens e/ou visitas técnicas não colaboraram com a aprendizagem dos conteúdos trabalhados em sala e outro não soube responder a questão $(2,2 \%)$. 
Na segunda questão (Nas viagens e/ou visitas técnicas realizadas pela faculdade você acredita que os professores conseguem relacionar o conteúdo teórico dado em sala de aula com a prática?) a maioria dos participantes $(71,1 \%)$ respondeu que sim, $26,7 \%$ responderam “às vezes" e um único estudante (2,2\%) respondeu negativamente. Diante disso, acreditamos que a prática educacional aplicada é uma excelente forma de se trabalhar e com isso o aluno passar a ter uma forma mais reflexiva do espaço no qual ele está envolvido.

Ao serem questionados sobre a importância da faculdade realizar viagens e/ou visitas técnicas interdisciplinares, ou seja, que relacionem o conteúdo das diversas disciplinas numa mesma viagem e/ou visita técnica, a maioria $(73,3 \%)$ respondeu ser muito importante esta relação. $13,3 \%$ responderam "razoavelmente". Outros $13,3 \%$ não perceberam esta importância ou não souberam opinar. Ao refletirem acerca da importância da rea lização de viagens e/ou visitas técnicas com o objetivo de conhecer melhor a cultura, a história, a geografia e a economia dos lugares, 95,6\% responderam ser muito importante. Segundo Gagné (1971), esse tipo de atividade possibilita a aplicabilidade e a verificação dos conceitos trabalhados em sala, uma vez que são componentes do ambiente da aprendizagem que dão origem à estimulação para o aluno adquirir um conhecimento amplo em uma só viagem.

Tabela 1 - Avaliação da importância das viagens e/ou visitas técnicas realizadas pela faculdade para o aprendizado

Total

Em sua opinião as viagens e/ou visitas técnicas colaboraram com a aprendizagem do conteúdo trabalhado em sala de aula?

Colaboraram muito

Razoavelmente 577,8

Colaboraram pouco

Não colaboraram

Não sei responder

Nas viagens e/ou visitas técnicas realizadas pela faculdade você acredita que os professores conseguem relacionar o conteúdo teórico dado em sala de aula com a prática? 
Às vezes

Nunca

Acha importante a faculdade realizar viagens e/ou visitas técnicas interdisciplinares, ou seja, que relacionem o conteúdo das diversas disciplinas numa mesma viagem e/ou visita?

Muito importante 3

Razoavelmente

Pouco importante

Nada importante

Não sei responder

Acha importante para a sua formação participar de viagens e/ou visitas técnicas com o objetivo de conhecer melhor a cultura, a história, a geografia e/ou a economia dos lugares?

Muito importante

Razoavelmente

Fonte: os autores

Em seguida, os estudantes que afirmam ser importantes tais atividades foram levados a citar alguns pontos positivos. Dentre os itens citados apareceram: o conhecimento adquirido $(82,2 \%)$, a organização $(28,9 \%)$, o planejamento das atividades $(22,2 \%)$ e a prática $(17,8 \%)$. Ressaltamos que os participantes poderiam escolher mais de um ponto.

Ao citar os possíveis pontos negativos a maioria dos participantes $(80,0 \%)$ respondeu que não há. Entretanto o custo (17,8\%) e o transporte (2,2\%) foram citados como elementos que podem dificultar a participação nas viagens ou visitas técnicas. Vemos, assim, que tais pontos acabam sendo mais específicos quanto à logística dos eventos, não sendo algo direcionado para o processo de ensino e aprendizagem. Solicitados a dar sugestões para melhorar as atividades no ambiente externo da faculdade, 40,0\% citaram a importância do "incentivo", ou seja, que a faculdade, de alguma forma, precisa incentivar mais os alunos a participarem de eventos externos. 
Gráfico 2 - Frequências percentuais dos pontos positivos para a formação em participar de viagens e/ou visitas técnicas organizadas pela faculdade / Paradise Turismo

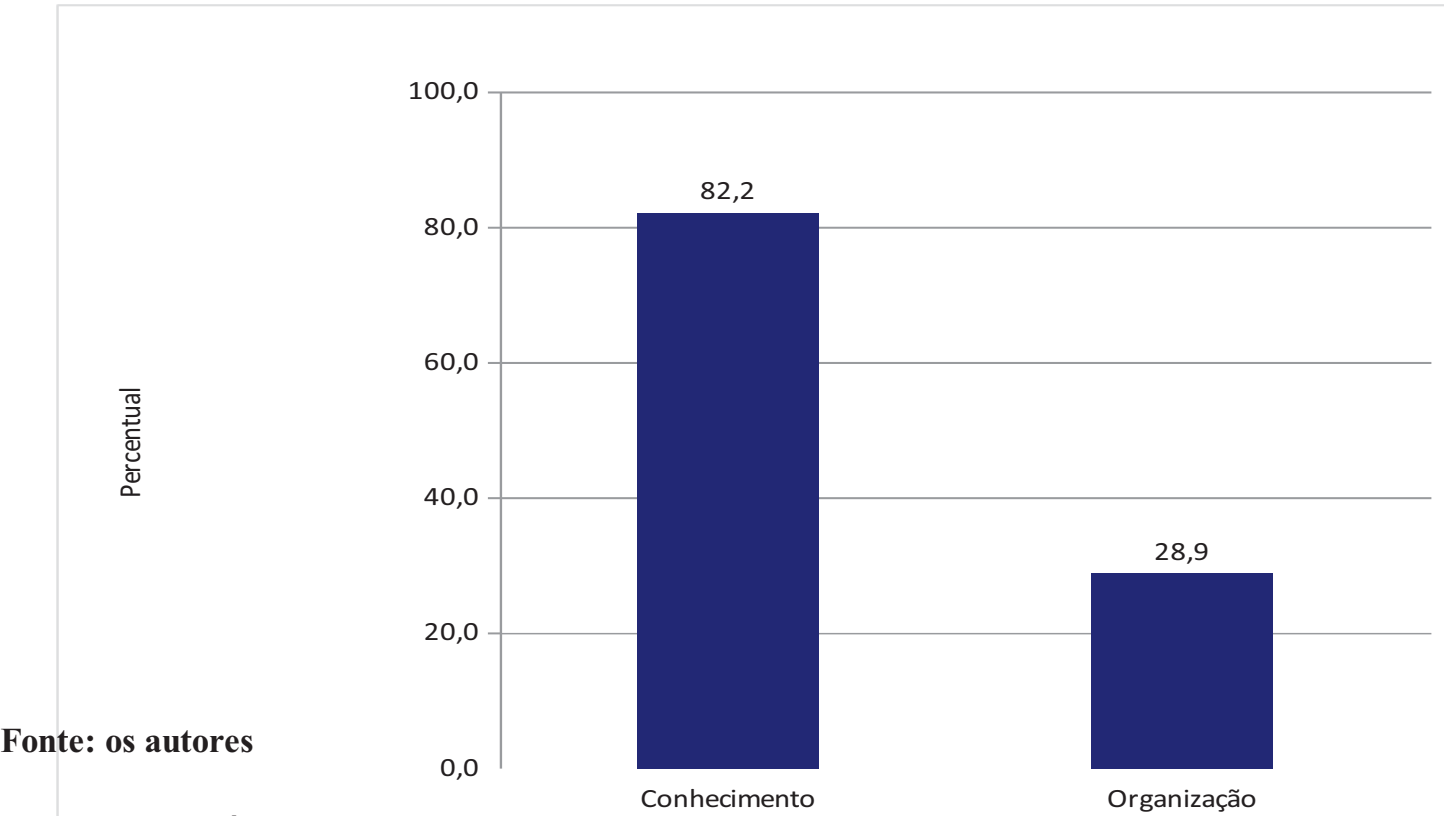

Gráfico 3 - Frequências percentuais dos pontos negativos para a formação em participar de viagens e/ou visitas técnicas organizadas pela faculdade / Paradise Turismo

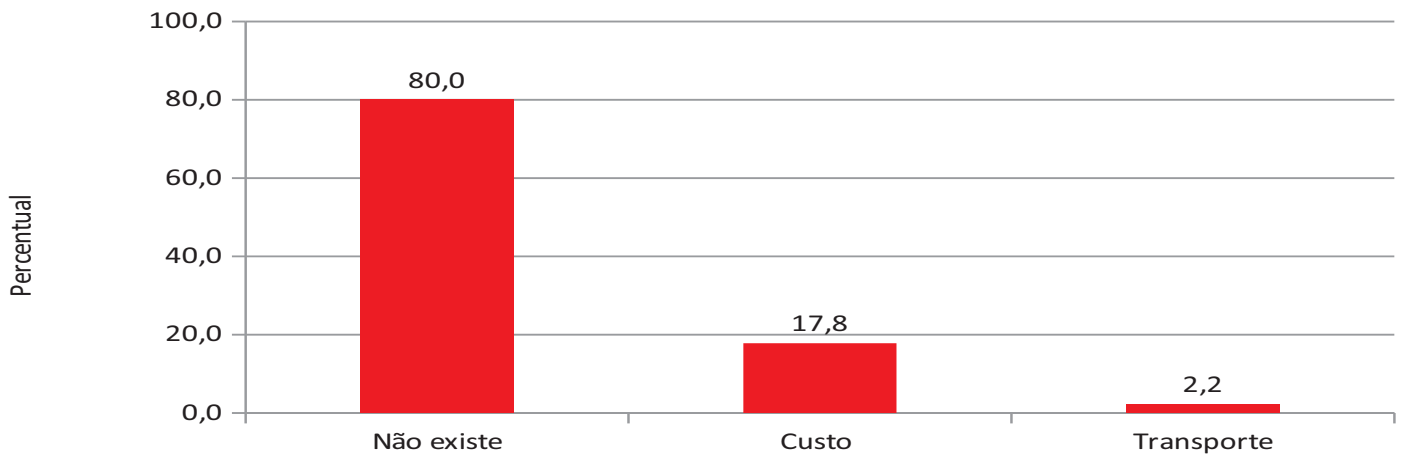

Pontos negativos

Fonte: os autores

Ao compararmos os pontos positivos e negativos percebemos que, de acordo com os estudantes, há mais pontos positivos que negativos ao realizar atividades de visitas técnicas atreladas às disciplinas do currículo da graduação.

De maneira geral é possível observar que, de acordo com os discentes, tal prática favorece o aprendizado e, consequentemente, a formação dos estudantes do Ensino Superior. 


\section{CONSIDERAÇÕES FINAIS}

De acordo com o presente trabalho, conclui-se que o turismo pedagógico é muito importante na vida acadêmica dos estudantes, pois auxilia no desenvolvimento e na aprendizagem durante o curso, ajudando também na vida profissional.

Dessa forma, acreditamos que é de grande importância para as faculdades investirem nas visitas técnicas ou pesquisas de campo, pois é uma atividade que desperta interesse nos discentes. O conhecimento adquirido através do turismo pedagógico funciona como uma ferramenta de aprendizado para a carreira profissional em vista de um mercado cada vez mais exigente.

A pesquisa também identificou que a maioria dos discentes já tinha realizado atividades pedagógicas e que eles achavam importante para a sua formação vivenciar, na prática, o conteúdo abordado pelos docentes nas salas de aula. Portanto, este trabalho, além de confirmar que o turismo pedagógico auxilia na aprendizagem dos conteúdos das disciplinas do seu currículo, também expõe as diversas possibilidades e contribuições que o turismo pode oferecer à educação.

Consideramos, portanto, a potencialidade do turismo pedagógico como um método diferenciado na educação, pois essa atividade pode possibilitar uma experiência enriquecedora. Acreditando nisso, esse trabalho aparece como uma alternativa de reflexão sobre a importância do turismo pedagógico para o ensino/aprendizagem.

\section{REFERÊNCIAS}

BARRETO, Margarita. Manual de iniciação ao estudo do turismo. 13. ed. Campinas: Papirus (Coleção Turismo), 2003.

BARRETO, Margarita.; REJOWSKI, Mirian. Turismo: interfaces, desafios e incertezas. Caxias do Sul: EDUCS, 2001.

BENI, Mário Carlos. Análise estrutural do turismo. 7. ed. São Paulo: Senac, 2001.

BRASIL. Ministério do Turismo. Marcos Conceituais: Segmentação do Turismo. Coordenação Geral de Segmentação, 2010. Disponível em: http://www.turismo.gov.br/sites/default/turismo/o_ministerio/publicacoes/downloads_publica coes/Marcos_Conceituais.pdf. Acesso em: 25 set. 2019. 
CUNHA, Maria Carolina da Silva. Turismo educacional: que viagem é essa? São Paulo, 2002.

Disponível

em:

http://www.unibero.edu.br/download/revistaeletronica/Set_Artigos/Turismo\%20educacional. pdf. Acesso em: 30 set. 2019.

CUNHA, Maria Isabel. Trajetórias e Lugares de Formação da Docência Universitária: da perspectiva individual ao espaço institucional. Brasília DF: CAPES/ CNPq, 2010.

DAMASCENO, Pedro. Turismo - uma actividade transversal. Blog Face Oculta. Jornal Ilha Maior. Açores, 2006. Disponível em: http://cronicasilhadopico .blogspot.com/2006/10/turismo-uma-actividade-transversal.html. Acesso em: 22 ago. 2019.

JUNQUEIRA, Sérgio; SCREMIN, Juliane. Aprendizado diferenciado: turismo pedagógico no âmbito escolar. Curitiba: Caderno de Estudos e Pesquisa do Turismo. v. 1, p. 26-42, jan/dez, 2012. Disponível em: https://docplayer.com.br/41274631-Aprendizado-diferenciadoturismo-pedagogico-no-ambito-escolar.html. Acesso em: 11 ago. 2019.

GASTAL, Susana. Turista cidadão: uma contribuição ao estudo da cidadania no Brasil. XXXIX Congresso Brasileiro de Ciências da Comunicação - UnB. Brasília, DF: INTERCOM, $2006 . \quad$ Disponível em: http://www.portcom.intercom.org.br/pdfs/153045190808854777108231357126206582002.pd f. Acesso em: 18 jul. 2019.

LICKORISH, L; JENKINS, L. C. Introdução ao turismo. 7. reimp. Rio de Janeiro: Elsevier, 2000 .

MOESCH, Marutschka. A produção do saber turístico. 2. ed. São Paulo: Contexto, 2000.

OLIVEIRA, Antônio Pereira. Turismo e desenvolvimento: planejamento e organização. 5. ed. São Paulo: Atlas, 2005.

OMT. Organização Mundial do Turismo. Introdução ao turismo. Tradução de Dolores Martin Rodriguez Córner. São Paulo: Roca, 2001.

REJOWSKI, Mirian. Turismo no percurso do tempo. 2. ed. São Paulo: Aleph, 2002. 


\section{Apêndice A - Roteiro do questionário a ser respondido pelos estudantes}

Curso:

Período:

Idade:

1) Você já participou de viagens e/ou visitas técnicas realizadas pela sua faculdade através da Paradise turismo?

( ) $\operatorname{Sim}$ ( ) Não

Se respondeu "Não" por que nunca participou?

Se respondeu "Sim" continue a entrevista.

2) Os seus professores já realizaram atividades no ambiente externo da faculdade?

( ) $\operatorname{Sim}$ ( ) Não

Se sim, cite as atividades que os seus professores já fizeram fora da faculdade nos últimos 3 anos.

3) Em sua opinião as viagens e/ou visitas técnicas colaboraram com a aprendizagem do conteúdo trabalhado em sala de aula?
( ) Muito
( ) Razoavelmente
( ) Pouco
( ) Não colaboraram
( ) Não sei responder

4) Nas viagens e/ou visitas técnicas realizadas pela faculdade você acredita que os professores conseguem relacionar o conteúdo teórico dado em sala de aula com a prática?

( ) Sempre

( ) Às vezes 

( ) Pouco
( ) Nunca
( ) Não sei responder

5) Você acha importante a faculdade realizar viagens e/ou visitas técnicas interdisciplinares, ou seja, que relacionem o conteúdo das diversas disciplinas numa mesma viagem e/ou visita?

( ) Muito importante

( ) Razoavelmente

( ) Pouco importante

( ) Nada importante

( ) Não sei responder

Por favor, justifique sua resposta.

6) Você acha importante para a sua formação participar de viagens e/ou visitas técnicas com o objetivo de conhecer melhor a cultura, a história, a geografia e/ou a economia dos lugares?
( ) Muito importante
( ) Razoavelmente
( ) Pouco importante
( ) Nada importante
( ) Não sei responder

7) Como você avalia a organização e o planejamento das viagens e/ou visitas técnicas realizadas pela faculdade através da Paradise Turismo?
( ) Muito bem planejadas
( ) Bem planejadas
( ) Pouco planejadas
( ) Mal Planejadas
( ) Não sei responder

8) $\mathrm{Na}$ sua opinião quais são os pontos positivos para a sua formação em participar de viagens e/ou visitas técnicas organizadas pela faculdade / Paradise Turismo?

9) Na sua opinião quais são os pontos negativos para a sua formação em participar de viagens e/ou visitas técnicas organizadas pela faculdade / Paradise Turismo? 
10) Você saberia dizer o que a faculdade poderia fazer para melhorar as viage ns e/ou visitas técnicas no ambiente externo da instituição?

11) Comente sobre a importância do turismo como vetor do conhecimento na sua formação acadêmica. 